\title{
UMA NOVA ESPÉCIE DE CALYPTRANTHES (MYRTACEAE) DA FLORA DO RIO DE JANEIRO, BRASIL
}

Recebido em 02.08.94. Aceito em 06.02.96.

\author{
Graziela Maciel Barroso ${ }^{1}$ \\ Ariane Luna Peixoto ${ }^{2}$
}

\begin{abstract}
RESUMO - (Uma nova espécie de Calyptranthes (Myrtaceae) da flora do Rio de Janeiro, Brasil). É descrita uma nova espécie para o gênero Calyptranthes (Myrtaceae), ocorrente na Reserva Biológica do Tinguá, município de Nova Iguacú, Rio de Janeiro. Trata-se de árvore ou arvoreta do estrato intermediário ou inferior da floresta atlântica que se destaca pela pilosidade densa e rufa de seus raminhos, pecíolos e dorso foliar. Pela sua forma de crescimento com copa pequena e arredondada e beleza de seus ramos esfoliantes, a nova espécie tem aptidão ornamental como arvoreta para áreas sombreadas.
\end{abstract}

Palavras chave: Calyptranthes, Myrtaceae, floresta atlântica

\begin{abstract}
A new species of Calyptranthes (Myrtaceae) from Rio de Janeiro, Brazil), occuring on the Tinguá Biological Reserve in the municipality of Nova Iguaçú, Rio de Janeiro state, is described. It is a small tree from the intermediate or inferior layer of the Atlantic forest and is conspicuous because of the dense, reddish indumentum on its branches, petioles and lower blade surface. Due to its architectural form with small rounded canopy and the beauty of its exfoliating branches, the new species may prove useful for ornamental plantings in shady areas.
\end{abstract}

Key words - Calyptranthes, Myrtaceae, Atlantic forest.

\section{Introdução}

Os inventários florísticos e fitossociológicos realizados por equipes de pesquisadores de diversas instituições brasileiras, em áreas remanescentes de floresta atlântica, no sudeste brasileiro, trouxeram à luz, entre os muitos outros resultados obtidos, algumas espécies novas para a ciência e outras tantas raras, conhecidas anteriormente apenas pelas coleções que as tipificavam.

\footnotetext{
${ }^{1}$ Jardim Botânico do Rio de Janeiro, Rua Pacheco Leão 915, 22460-030, Rio de Janeiro - RJ, Brasil. Bolsista do CNPq.

${ }^{2}$ Universidade Federal Rural do Rio de Janeiro,Instituto de Biologia, Caixa Postal 74582, 23851-970, Seropédica, Itaguai-RJ, Brasil. Bolsista do CNPq.
} 
Nos inventários fitossociológicos já realizados em remanescentes de floresta atlântica, as Myrtaceae aparecem listadas entre as dez famílias mais importantes quer em número de espécies quer em número de indivíduos. Frequentemente são listadas entre as três famílias mais importantes, o que mostra a relevância desta família nesta floresta (Peixoto et Gentry 1990; Mello 1993, entre outros).

De sistemática difícil, a classificação das espécies dessa família tem sido tarefa árdua que requer, frequentemente, a análise de coleções extensas, de materiais tipo e grande amadurecimento taxonômico refletido na intimidade com a literatura especializada e no convívio com especialistas do grupo.

O gênero Calyptranthes, em especial, foi objeto de estudo de Berg (1857), na Flora Brasiliensis, de Legrand $(1962$ e 1971), de Mc Vaugh $(1958,1969)$ e Barroso et Peixoto (1995).

A espécie descrita no presente trabalho espelha a dificuldade de atribuir-se nome, quer como espécie nova, quer como espécie já conhecida, a táxons dessa família devido a complexa relação entre eles, aliado a sua grande representação numérica nos diferentes remanescentes de mata atlântica.

\section{Descrição da espécie}

\section{Calyptranthes ursina Barroso et Peixoto sp.nov.}

Arbor vel frutex, ramis teretibus, dichotomis, exophloe delapso, glabratis, junioribus indumento hirsuto ferrugineo dense vestitis. Folia lanceolata, petiolata, papyracea, versus apicem attenuata, basi acuta, $8-9 \mathrm{~cm}$ longa, $2-3 \mathrm{~cm}$ lata, supra glabra, lucida, subtus exepto nervo medio glabrata, petiolo ca. $5 \mathrm{~mm}$ longo hirsuto, nervo medio supra subimpresso, subtus prominulo et dense hirsuto, venis lateralibus tenuibus utrinque latere 20-22 subpatulis, venulis interjectis tenuioribus ramosis et reticulatis alveolos laxos formantibus, duplo-limbinervis a margine ca. $1 \mathrm{~mm}$ remotis. Florescentiae dense hirsutae 2-3 terminales, base bibracteatae, pedunculo terete 5$8 \mathrm{~cm}$ longo, apice parce dilatato, 2-3 ramos $3-4 \mathrm{~cm}$ longos apice furcatos fulciat. Ramusculi 2-3, 1,5-2 cm longi apice 3-floribus sessilibus conglomeratis inter bracteolas cataphyllaceas ramorum bifurcationi affixi. Alabastrum ovoide ca. $3 \mathrm{~mm}$ longum, operculo membranaceo et petalis minutissimis. Fructus in specime nostro desunt.

Holotypus - Rio de Janeiro, município de Nova Iguacú, Reserva Biológica de Tinguá, caminho de Barrelão à Reunião, duas curvas antes de chegar a represa, lado esquerdo, 14.12.1991 (fl.), S. J. Silva Neto 04. (RBR; Isotypus RB)

Paratypus - Rio de Janeiro, Nova Iguaçú, Reserva Biológica de Tinguá, 09.11.93 (fl.) A. L. Peixoto et S. J. Silva Neto 1988 (RBR, RB).

Arvoreta ou arbusto até $2,5 \mathrm{~m}$ alt., com fuste de ca. $1 \mathrm{~m}$ compr., ritidoma pardacento, esfoliante; ramificação dicotômica, ramos esfoliantes, glabros quando adultos, 


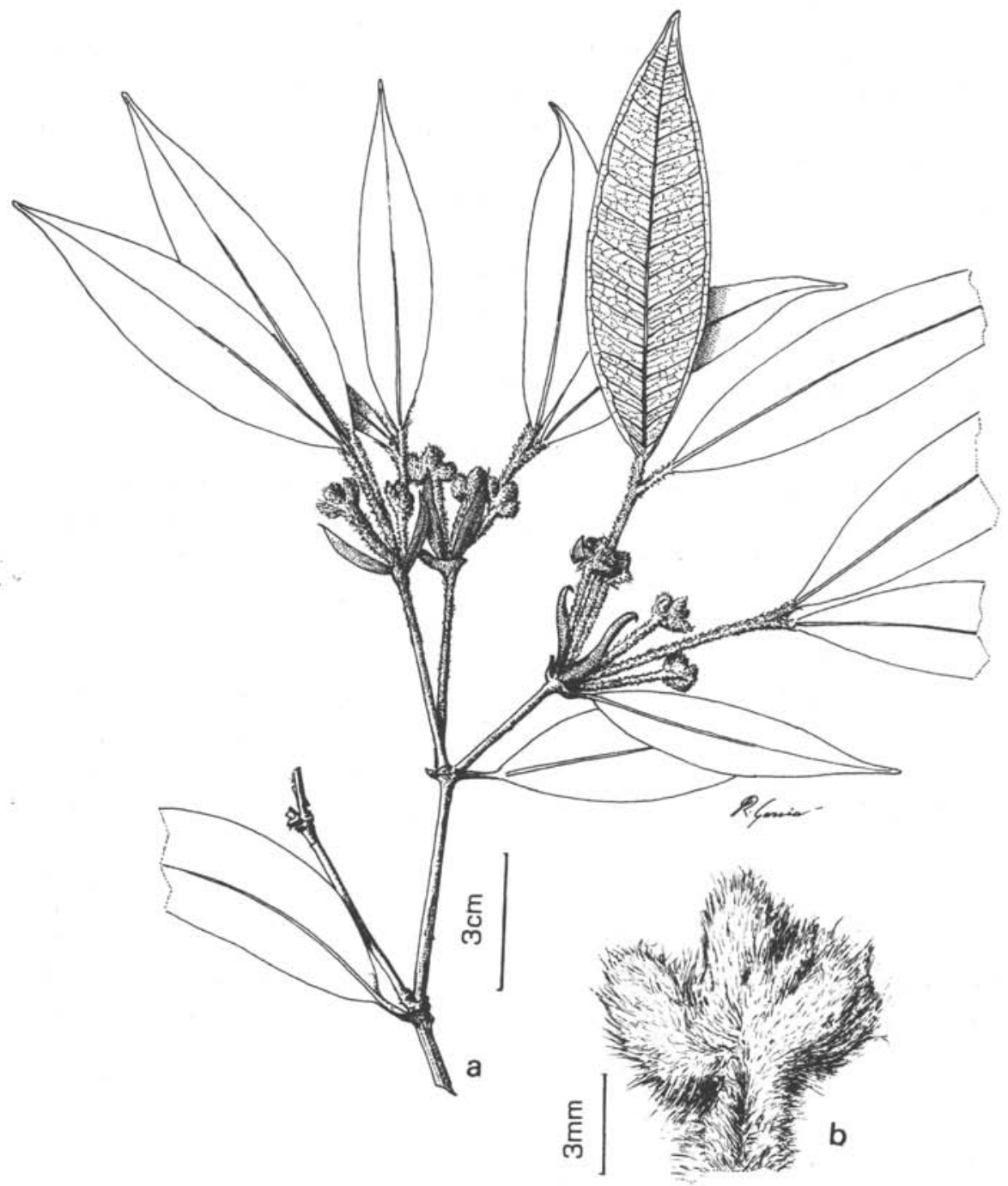

Figura 1. A: habito; B: detalhe da parte terminal da inflorescência (S.J. Silva Neto 04).

raminhos novos, pecíolos, nervura média na parte dorsal do limbo, inflorescências e botões florais densamente revestidos por indumento de tricomas hirsutos, mais ou menos longos, ferrugíneos. Folhas lanceoladas, papiráceas, atenuadas em direção do ápice, base aguda, $8-10 \mathrm{~cm}$ compr., $2-3 \mathrm{~cm}$ larg., lúcidas, densamente pilosas quando jovens, glabras a glabrescentes quando adultas, obscuramente pontuadas, nervura mediana imersa na face ventral, e na face dorsal um tanto saliente, nervura média densamente 
coberta por tricomas ferrugíneos, hirsutos; nervuras laterais finas, mas perfeitamente conspícuas, mais ou menos patentes, 20-25 pares, as intersecundárias mais tênues, ramificadas reticuladas, formando alvéolos mais ou menos laxos, nervuras marginais em número de duas, uma mais interna, tão espessada quanto as laterais, formando laços a cerca de $1 \mathrm{~mm}$ de distância do bordo e outra, tenuíssima, quase obsoleta, mais próximo ao bordo do limbo. Inflorescências 2-3 nos ramos terminais, densamente ferrugíneohirsutas, pedúnculo cilíndrico, $5-8 \mathrm{~cm}$ compr., bibracteado na base, um pouco alargado e bibracteado no ápice, de onde saem, geralmente, 3 ramos $3-4 \mathrm{~cm}$ compr. providos de 2 brácteas apicais e, sobre eles, na axila de bracteolas catafiloides, 1-2cm compr. 0,3$0,5 \mathrm{~cm}$ larg., ordenam-se de 2-3 raminhos férteis, com 1,5-2cm compr., em cujo ápice aglomeram-se 3 botões florais. Botões florais ca. de $0,3 \mathrm{~cm}$ compr., ovóides, antese caliptriforme, com opérculo membranáceo curto e pétalas diminutas e glabras.

O binômio específico alude ao indumento denso, de pêlos hirsutos e ferrugíneos. Os exemplares examinados na Reserva Biológica do Tinguá são notórios pela beleza de suas formas, com fuste retilíneo, copa pequena, arredondada e densa folhagem, sendo as lâminas foliares marcadas pela nervura central densamente ferrugíneopilosa. Nos ramos mais sombreados se conserva por mais tempo a pilosidade hirsuta e ferrugínea do dorso das folhas. Por estas características a espécie pode ser aproveitada em paisagismo de interior ou de áreas sombreadas.

A espécie é afim de Calyptranthes strigipes Berg, $C$. concinna DC. e C. pileata Legr., mas distingue-se pelo indumento de pêlos hirsutos, pelo padrão de venação das folhas e por característica das inflorescências. De C. strigipes Berg, árvore de 15 a $20 \mathrm{~m}$ de altura, distingue-se especialmente pela presença de indumento de pêlos vilosos, mais ou menos denso e ocráceo, nesta espécie. C. concinna DC. possui indumento de pêlos curtos, adpressos, vermelho-amarelado ou pardo, misturados com pêlos alvos, dibraquiados ou escamosos e pêlos setulosos ao longo das nervuras. C.pileata Legrand apresenta inflorescências paniculóides axilares, com 5 a $6,5 \mathrm{~cm}$ de comprimento, com dois ramos laterais delgados com 1-3 flores de sésseis a quase sésseis. Por estes caracteres, dentre outros menos notórios, a espécie é perfeitamente distinta.

\section{Referências bibliográficas}

Barroso, G.M. et Peixoto, A.L. 1995. Myrtaceae da Reserva Florestal de Linhares, Espírito Santo, Brasil. Gêneros Calyptranthes e Marlierea. Bol. Mus. Biol. Mello Leitão (N.Ser.) 3:3-38.

Berg, O. 1857. Myrtaceae. In Martius, C.F.P., Eichler, A.G. E Urban, I. (eds.) Flora Brasiliensis 14 (1): 1665 et suppl: $516-656$.

Legrand, C.D. 1962. El genero Calyptranthes en el Brasil Austral. Lilloa 31: 152-206.

Legrand, C.D. 1971. Calyptranthes S. W. In: Reitz, R. (ed.), Fl. Ilustr. Catarinense : 419-552.

Mc Vaugh, R. 1958. Myrtaceae (Calyptranthes and Marlierea). In.: Maguire, B. et Wurdack, J.J., The Botany of Guayana Highland. Part. III. Mem. New York Bot. Gard. 10: 61-91.

Mc Vaugh, R. 1969. Myrtaceae. In.: Maguire, B. et Wurdack, J.J. (eds.). The Botany of Guayana Highland. Part. VIII. Mem. New York Bot. Gard. 18(2): 55-286. 
Melo, M.M.F. de. 1993. Composição florística e estrutura de um trecho de mata atlântica de encosta na Ilha do Cardoso (Cananéia, São Paulo, Brasil). Tese de Mestrado. Instituto de Biociências, Universidade de São Paulo.

Peixoto, A.L. \& Gentry, A. 1990. Diversidade e composição florística da mata de tabuleiro na Reserva Florestal deLinhares (Espírito Santo, Brasil). Rev. Bras. Bot. 13(1): 19-25. 